\title{
ANALYSING STUDENT TOURIST MOVEMENT BASED ON THE UTILITY MAXIMISATION IN DESIGNING TOUR PACKAGE IN JOHOR BAHRU
}

\author{
Isabel Anak Farid, Mohd Faisal bin Abdul Khanan*, Hafiz Aminu Umar, Zamri Ismail \\ Department Geoinformation, Faculty of Built Environment and Surveying, \\ Universiti Teknologi Malaysia, 81310, Johor Bahru, Malaysia \\ belcy95@gmail.com,mdfaisal@utm.my, abdulhafizamin@yahoo.com, zamriismail@utm.my
}

KEY WORDS: Tourism movement, Student Tourist, Utility Maximisation, Tour Package, Mode Model, Market Segmentation

\begin{abstract}
:
Tourism industry has played a vital role in the economic development of Malaysia by driving influx of people, capital and commodities into a potentially wealthy country. Tourism also contributed to a foreign exchange earning of most South East Asian countries including Malaysia. The aim of this paper is to analyse and understand the tourist movement pattern from utility maximisation point of view in reference to the spatial pattern of tour package design in Johor Bahru. Tourist movements from one destination to the other solely depends on the tourist attractions sites available in the area and this corresponds to tourist decision on where, when, how and what time to move from one attraction site to the other. The workflow of this study until the final product is the geospatial map of the tour package that has been statistically analyse from the design questionnaire issued to students on tourism aspects. The method used in identifying and determining the utility maximisation of the arrival time and duration time for each attraction is the mode model. From the statistical result, data validation has been constructed to identify whether the result obtain is significantly accepted or fit by using the elementary statistical test. The final output has been presented in various graph to identify the maximum utility for the arrival and time duration for tour package. *For example, tour package $\mathrm{G}$ contains Hutan Bandar, Johor Zoo, Johor Grand Palace, Jalan Tan Hiok Nee Bangunan Kedai Lama and Bazar Karat as the listed attractions together with their corresponding arrival times and durations of time spent.
\end{abstract}

\section{INTRODUCTION}

Tourism industry has contributed immensely to the economic and social development of many countries around the world. The development of tourism centre can boost economic growth, employment opportunities, and can be beneficial to both government and the residents respectively (Gursoy and Rutherford, 2004; Seetanah, 2011; Tao and Wall, 2009). Tourism also assist in maintaining peace and order as well as minimizing the perceive cultural differences between the host communities and the tourist (Fan et al., 2017). Malaysia has seen for over the years an influx of people from different part of the world due to numerous tourism attraction sites in the country. This has made Malaysia to emerge among the top 10 tourist destination in the world. Various cities and villages within the country offers different tourist attraction sites. Johor Bahru is one of the states in Malaysia that has various and interesting tourist attraction sites such as eco-tourism, city tour, golf field, amusement park and Johor mangrove park among others ("Tourism Malaysia Promotes 'Johor Holiday Packages,"” 2016)

Johor's greatest strength in tourism is it's fascinating nature of tropical climate which is generally warm with sun shine throughout the year. Additionally, the natural endowment of beaches and island scattered around the state as well as cultural diversity and friendly nature of the people has attracted many tourists from all over the world. Tourism sector in the country has generally contributed to about 8 to 10 percent of the gross domestic product (GDP) (Sivalingam, 2007). Therefore, promoting the attraction sites is an important aspect that showcase the location quality, and attract both domestic and foreign investors to invest in the sector.
However, most tourism planners focus solely on developing and planning of tourist attraction sites, neglecting one of the vital aspect that guarantees, safety, security and wellbeing of the tourist (Jane \& Marie, 2012). Tour package is essentially a tourism experience which tourist goes through during the vacation and it brings succour to many tourists that came to visits from different countries (Oh, Fiore \& Jeoung, 2007). Besides that, tour package is one of the reasonable and compelling way for tourist to travel in a safest way, visiting various places on a brief period and with full coordination from the tour administrators (Akova \& Cetin, 2017).

Tourist movements is an important factor that determines tourist satisfaction on whether the sites attraction has anything to write home about. The tourist satisfaction is crucial to the tourist industries and will earn much credit to the sector which in turn develop the economy of the host countries (Asakura \& Iryo, 2007). Therefore, the major influences on such movement and modelling is the basic spatial forms in understanding the tourist intra-destination movement patterns which is one of the conceptual challenges (Lew \& Mckercher, 2006).

Moreover, understanding the competitiveness and attractiveness of a destination, modelling and forecasting of tourism demands are basic to decision makers (Ferreira \& Pereira, 2014). Tourist pay much attention to the tourism experience utility tour. Planning a tour package to achieve the maximization of the tourism experience utility is through considering the tourist preference of time, attraction and budget (Wu, Guan, Han, \& Ma, 2017). Therefore, to achieve the maximization of tourism experience utility based on tourist preference, a utility maximization model is being employed in designing a tour package that satisfy the tourist demand. 
In order to utilize more interesting tour planning package, a Geographical Information System (GIS) technology can be useful in managing the tourism sector by applying the analytical tools and function. The analysis can be useful to the management in future planning of tourism development in the country (Abomeh \& Nuga, 2013). The travel routes on a map and common data around the range to visit are utilize by selecting the destination and arranging both travel and accommodation. The application of GIS in tourism industry has helped in solving numerous challenges encountered by tourist and tourism industries. Therefore, this study employed the application of GIS in modelling utility maximization in order to design the tour package by creating a geographical database that cover all tourist destination in Johor Bahru.

\section{METHODOLOGY}

The methodology for this study can be seen in the figure below;

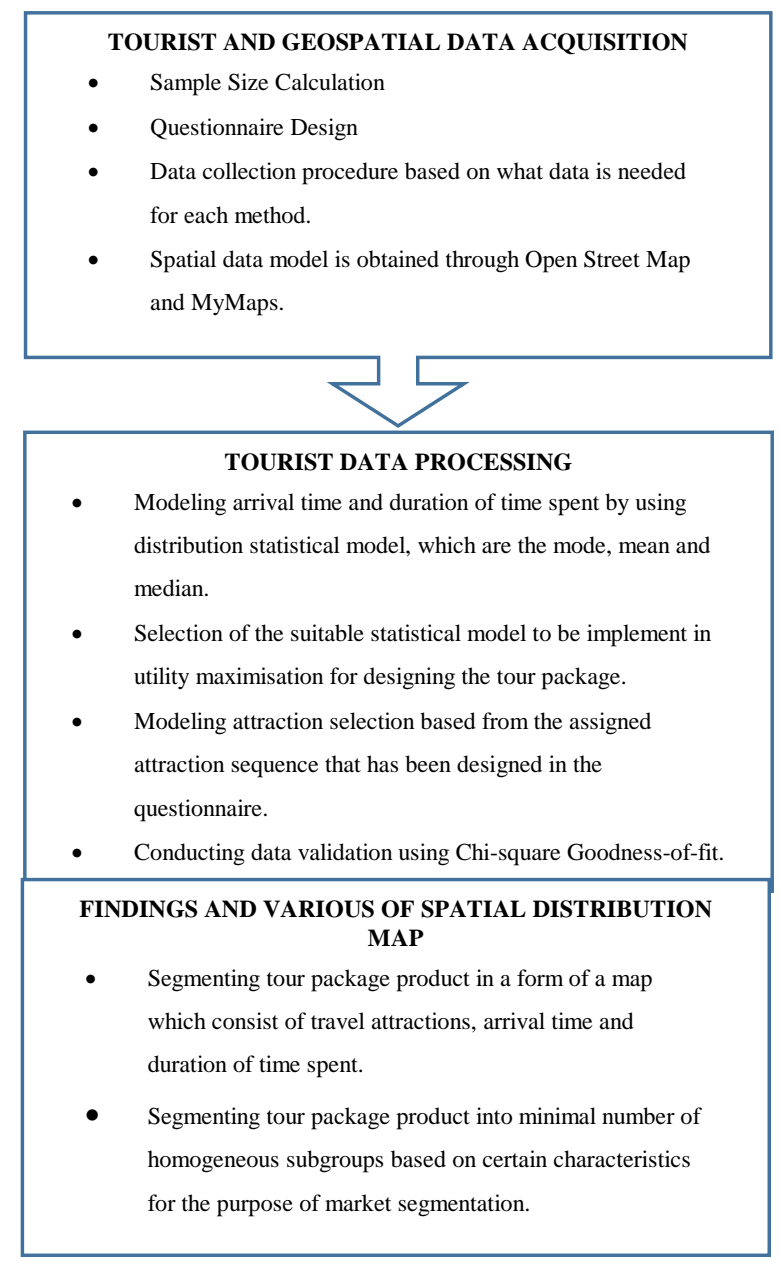

Figure 1. Flow study approach

\subsection{Tourist and Geospatial Data Acquisition}

Data collection and data acquisition focused on the procedure of how the collection of student tourist preferences can be obtained through the design of the questionnaire. Besides that, this phase will also briefly explain how spatial data model obtained through Open Street Map and MyMaps can be implemented in the design of the tour package map.

\subsection{Tourist Data Processing}

This phase focused on how the data acquired will be processed by applying the distribution statistical model in distinguishing the arrival time and duration of time spent for each attraction.

The method of interpretation was through descriptive statistics base on socio economic demography, points of interest, arrival and duration of time spend for each attraction sites. In order to fully utilise the maximisation of modelling a tour package, arrival of time and duration of time spending from one attraction sites to the other using the distribution data model which consist of, mode, mean and median data model has been used.

Studies related to tour packages development has been conducted by Khanan (2014), where he specifically mentioned the use of mode model as shown in equation 1 where $T_{i}^{*}$ is the mode to determine the transitional arrival time, derived from using PDF at attraction $i$.

$$
\max _{-\infty<<<\infty} f_{i}(T)=f_{i}\left(T_{i}^{*}\right) \text {. }
$$

Equation 1

while $f_{i}\left(T_{i}^{*}\right)$ has been evaluated by the mode, which is the highest occurrence of the repeated arrival times that the tourist has selected for the purpose of commercial activities in generating more profit for tour packages. Khanan also stated that the most suitable mode of transitional arrival time is determined by deriving its probability.

As for mode model that derived the best scheduling tourist movement, Khanan (2014) used the most attractive combinations where by the product rule of probability, the combination of attractions, which refer to the frequent visitors and the most common arrival time at each attraction sites which is known as the maximisation of $q$ as shown in the equation 2 . The $F$ is derived as the highest probability which considered as the recommended tour package for tourist.

$$
\begin{gathered}
F=\max \left(q_{i}\right) \\
\text { Equation } 2
\end{gathered}
$$

In this study, distribution data model of either max, mean, mode or median has been implement in determining the utility of the arrival time and the duration spend for each attraction. From there, an observation from all the four models has been compared and discovered why mode model is the best model in determine the arrival time for each of the attraction compared to the other three model.

The final step in interpreting the data is by applying the ChiSquare Goodness-of-fit test to ensure the quality level of the final data is valid. In regards to this test, the obtained sample from the data are called the observed frequencies, which is the $O$. The frequencies obtained by calculation are called the expected frequencies, which is the $E$. The observed frequencies and expected frequencies and will always be differing due to the sampling error.

$$
X^{2}=\Sigma \frac{(O-E)^{2}}{E}
$$

Equation 3

Besides the observe and expected frequencies, degree of freedom and level of significance too need to be obtain in order 
to calculate the critical value. In the goodness-of-fit test, the degree of freedom can be calculated using the number of categories minus with $1, D . f=r-1$. As for the level of significance, to ensure the probability of type I error for this study is $5 \%$, the level of significance been used is $\alpha=0.05$. The purpose of the level of significance is to identify the maximum probability of committing errors for this study. With the obtained degree of freedom value and the level of significance, the critical value known as $P$-value will determine the critical and noncritical region which indicates whether there is a significant difference or the differences was probably due to chance.

The Chi-Square statistics $X^{2}$ and the $P$-value has been compared. If $X^{2}$ value is outside the $P$-value, it can therefore be conclude that the observed frequencies are compatible with the expected frequencies and the model will provides a good fit of the data (Moore et al., 2012). Besides the observe and expected frequencies, degree of freedom and level of significance too need to be obtain in order to calculate the critical value. In the goodness-of-fit test, the degree of freedom can be calculated using the number of categories minus with $1, D . f=r-1$.

\subsection{Findings of Various Spatial Distribution Maps}

The findings and various spatial distribution maps can be obtained by segmenting the tour packages products such as itineraries, attractions and activities (Khanan, 2014). Based on the results of modelling a tour package in section 2.3, the practice of simple market segmentation into minimal number of homogeneous subgroups based on certain characteristics are shown below;

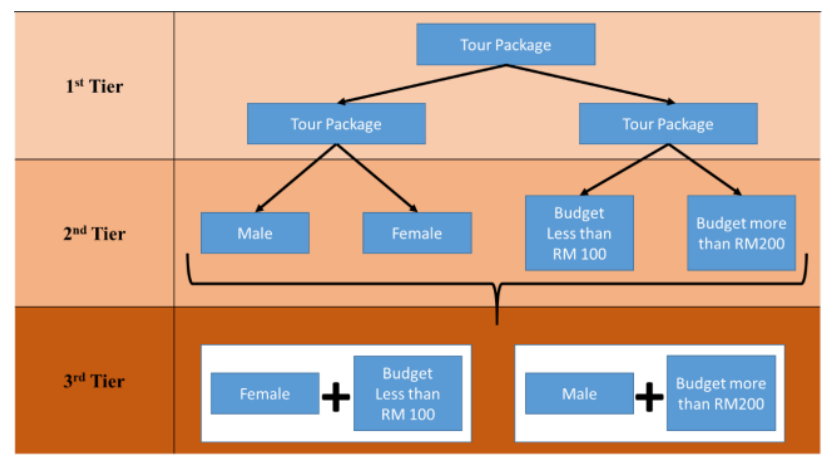

Figure 2: The hierarchy of spatial distribution maps

\section{RESULTS AND DISCUSSION}

\subsection{Descriptive Statistics}

The descriptive statistics were obtained through administering of 245 questionnaires, where 228 questionnaires are valid while 17 questionnaires were invalid.

From the 228 valid questionnaires, about $62.3 \%$ of the respondent are female while $37.7 \%$ are male. As for the descriptive statistics for tour package that has been assigned, each respondent was asked to select two out of 13 assigned attraction sequence and one selected of their choices. Likewise, based on figure 3, the highest choice of selection assigned attraction sequence was Package A, followed by package B and package G. Fortunately, these particular assigned attraction sequence has already been earmarked for modelling the tour package as refer in Section 3.2 for knowing the attractions for these for particular packages. An assigned attraction sequence does not show the student tourist preferences and the tourist movement of attraction sequences for most of the selection are the same.

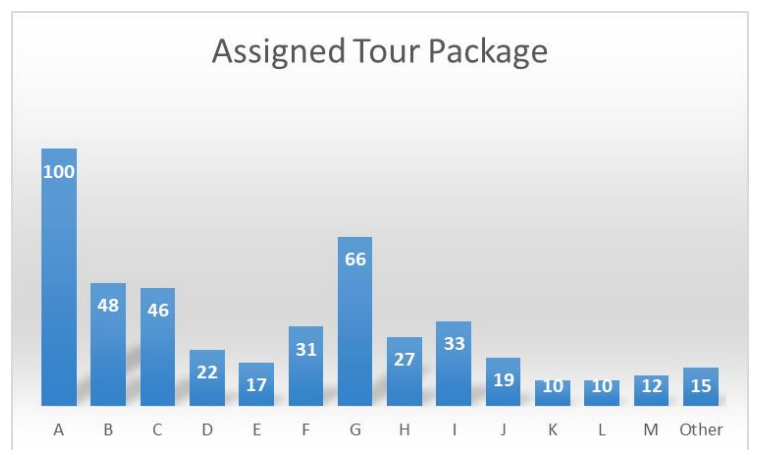

Figure 3: Assigned selection tour package sequence

However, the descriptive statistics of the budget, shown in figure 4 indicates that most of the student tourist package will not exceed RM 101 to RM200 for a one-day travel in Johor Bahru and this is done without considering the type of assigned attraction sequences.

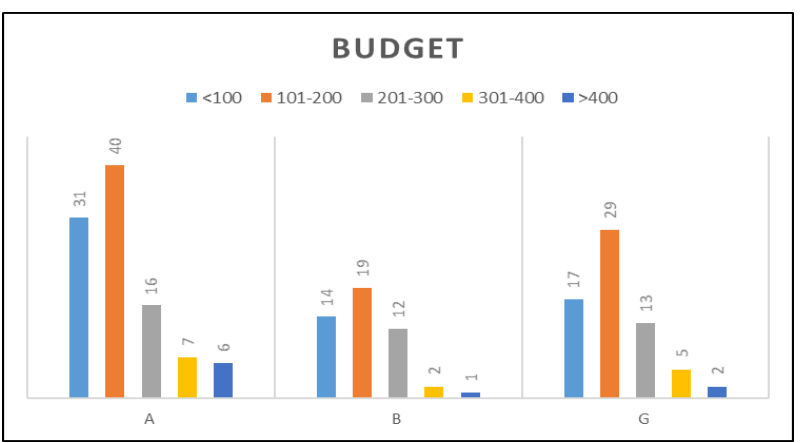

Figure 4: Budget in corresponding to type of assigned attraction sequence.

The movement pattern of the student tourist been obtained is within Johor Bahru and it's based on their interest for sites attraction. Although the sequence of attraction for one-day trip from the 12 assigned attraction sequence pattern can still be seen.

From the data that has been collected, the type of attraction that caught the attention of the student tourist is the natural attractions. Figure 5, shows that the top choices of attraction category that the students prefer to visit is a one-day tour in Johor Bahru which falls within the Natural and Parks category, followed by Theme and Amusement Park category as wells as the shopping malls category.

According to Goeldner and Ritchie (2009), the natural attractions are the main purpose that caught people's attention. For example, countries that has great national park such as United States, Canada, and Japan attract millions of visitors. The wonders of those parks lure tourist to visit and enjoy the natural beauty, recreation and inspiration, which the park has provided.

The possibility of creating the best fit of travel tour package is to understand the exact match between the tour package and the corresponding demand from the tourist interest. From there, the 
attraction category can be considered as the activity-based models in modelling the right tour package which refer to the tourist preferences of interest attraction they wish to visit and participate.

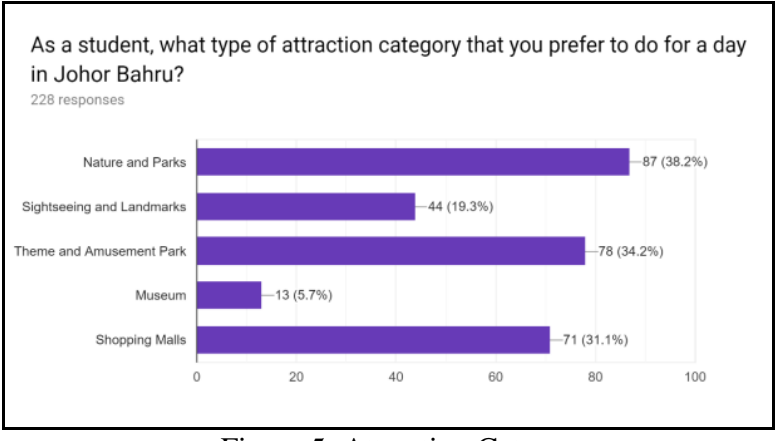

Figure 5: Attraction Category

\subsection{Tour Package}

In reference to section 3.1 the descriptive statistics on assigned selection of tour package, the top 3 most popular tour package are tour A, B and $\mathrm{G}$ in reference to Table 1 below.

\begin{tabular}{|l|c|l|}
\hline \multicolumn{2}{|c|}{ Attraction Sequence Code } & \multicolumn{1}{|c|}{ Name Of Attractions } \\
\hline \multirow{4}{*}{ A } & A1 & Johor Zoo \\
\cline { 2 - 3 } & A2 & Hutan Bandar Recreational Park \\
\cline { 2 - 3 } & A3 & Jalan Tan Hiok Nee Bangunan Kedai Lama \\
\cline { 2 - 3 } & A4 & Bazaar Karat \\
\cline { 2 - 3 } & A5 & Danga Bay Amusement Park \\
\hline \multirow{4}{*}{ B } & B1 & Johor Zoo \\
\cline { 2 - 3 } & B2 & Johor Grand Palace \\
\cline { 2 - 3 } & B3 & Jalan Tan Hiok Nee Bangunan Kedai Lama \\
\cline { 2 - 3 } & B4 & Bazaar Karat \\
\cline { 2 - 3 } & B5 & Danga Bay Amusement Park \\
\hline \multirow{5}{*}{ G } & G1 & Hutan Bandar Recreational Park \\
\cline { 2 - 3 } & G2 & Johor Zoo \\
\cline { 2 - 3 } & G3 & Johor Grand Palace \\
\cline { 2 - 3 } & G4 & Jalan Tan Hiok Nee Bangunan Kedai Lama \\
\cline { 2 - 3 } & G5 & Bazaar Karat \\
\cline { 2 - 3 } & G6 & Danga Bay Amusement Park \\
\hline
\end{tabular}

Table 1: List of Attractions for Attraction Sequence A,B and G

Therefore, from all the three assigned attractions sequence various times of arrivals and duration of time spend for each attraction have been stated. Table 2, below shows the distribution of data model of arrival time and duration time that has been derived according to the following four type of model for every attraction sequence. Particularly, student tourist can estimate their possible arrival time for each attraction when the mode of the arrival time of tourist is anticipated.

According to Khanan (2014), the starting time of activities for each attraction depends on the number of tourists arriving at a specific time which make it necessary to identify the mode of arrival time of tourist. He also stated that, the duration of time spend for each attraction can influence the tourist arrival time for the next attraction which will cause the unimodality scenario.

While the maximum model, identify the biggest value of element in a set of the data list. Unfortunately, inside the dataset, not all the respondent will select the highest value of preferences. In the world of statistics, mean model is one of the most popular and well-known measure of central tendency. In modelling the tour package, mean model is not suitable because the sum of every dataset is divided by the number of values in the data set. Therefore, the results of both arrival time and duration time will not be the actual values that has been observed in the dataset. Lastly, median model is a model of data set that identify the middle value for a set of data that has been arranged in order of magnitude which is less affected by outliers and skewed data. Unfortunately, in modelling tour package, median model is not a good representation in describing a data set with outliers, mainly because the median value is not inside the dataset.

The suggestion of arrival time and durations using mode model in selecting the best time of arrival and duration in modelling a tour package is mode model because it identifies the most frequent element that been repeatedly mention in the data list for both arrival time and duration which is why mode model is the most suitable model compare to the other three mod

Table 3 and 4 shows that out of these two attraction sequence, the expected time of departure for each attraction is by adding the arrival time and the duration time spend for each attraction which may not seem to be a problem. This is due to the differences in the time of departure from one attraction to the other. The time differences between the time of departure and arrival may provide an opportunity to a smooth transition from one attraction to the next with reference to the condition of the traffic and the distance travel.

The sequence of attractions $\mathrm{G}$ in Table 5 faces an issue of glitch within the departure time of attraction $\mathrm{G} 1$ and the arrival time of attraction G2. Therefore, the transition between attraction G1 and G2 will not be running smoothly as the student tourist will have to make a new decision either to shorten the duration time for attraction $\mathrm{G} 1$ or reschedule the arrival time for attraction $\mathrm{G} 2$.

The same issue has been repeated between attraction G5 and G6, as the time difference is equal to 0 hours. In that case, the student tourist will have to consider a new decision making either to shorten the duration time for attraction G5 or reschedule the arrival time for attraction G6.

As a matter of fact, Khanan (2014), stated that it is better to consider the visiting duration as 'arbitrarily assigned' based on the time frame between the two arrival times which is the former and latter attractions.

Apart from the time differences, the number of attraction visited for one-day trip for all three sequences is also different. Both attraction sequence $\mathrm{A}$ and $\mathrm{B}$ has five suggested attractions to visit whereas attraction in sequence $G$ has six suggested attractions. Ergo, a big differences of time in transition from one attraction to the other can be effected provided the tourist prefer to spend more time visiting other places than spending more time on the transportation mode.

Out of all of these three attraction sequence, the most suitable sequence for modelling one-day tour package in Johor Bahru is attraction sequence $\mathrm{G}$ as it has the reasonable time arrival and a slight difference between arrival time and expected arrival time. Therefore, the duration for this tour package will be arbitrarily assigned as shown in Figure 6. 
The International Archives of the Photogrammetry, Remote Sensing and Spatial Information Sciences, Volume XLII-4/W16, 2019 6th International Conference on Geomatics and Geospatial Technology (GGT 2019), 1-3 October 2019, Kuala Lumpur, Malaysia

\begin{tabular}{|c|c|c|c|c|c|c|c|}
\hline \multirow[b]{2}{*}{$\begin{array}{c}\text { Tour } \\
\text { Package }\end{array}$} & \multirow[b]{2}{*}{ Attraction } & \multicolumn{2}{|c|}{ Mode Model } & \multicolumn{2}{|c|}{ Mean Model } & \multicolumn{2}{|c|}{ Median Model } \\
\hline & & Arrival Time & $\begin{array}{c}\text { Duration } \\
\text { Time }\end{array}$ & Arrival Time & $\begin{array}{c}\text { Duration } \\
\text { Time }\end{array}$ & Arrival Time & $\begin{array}{c}\text { Duration } \\
\text { Time }\end{array}$ \\
\hline \multirow{5}{*}{ A } & A1 & $10: 00$ & $02: 00$ & $09: 52$ & $02: 00$ & $10: 00$ & 02:00 \\
\hline & $\mathrm{A} 2$ & $14: 00$ & 01:00 & $13: 28$ & $01: 39$ & $14: 00$ & 01:30 \\
\hline & A3 & $16: 00$ & 01:00 & $16: 09$ & 01:29 & $16: 00$ & 01:30 \\
\hline & A4 & $19: 00$ & 02:00 & $18: 46$ & 01:54 & $19: 00$ & 02:00 \\
\hline & A5 & 22:00 & 02:00 & $19: 55$ & 01:47 & 22:00 & 02:00 \\
\hline \multirow{5}{*}{ B } & $\mathrm{B} 1$ & $10: 00$ & 02:00 & $10: 06$ & 02:05 & $10: 00$ & 02:00 \\
\hline & $\mathrm{B} 2$ & $14: 00$ & 01:00 & $13: 28$ & 01:30 & $14: 00$ & 01:15 \\
\hline & B3 & $16: 00$ & 01:00 & $16: 00$ & $01: 36$ & $16: 00$ & 01:30 \\
\hline & $\mathrm{B} 4$ & 19:00 & 02:00 & $18: 46$ & 01:43 & 19:00 & 02:00 \\
\hline & B5 & $22: 00$ & 02:00 & $19: 28$ & 01:49 & $22: 00$ & 02:00 \\
\hline \multirow{6}{*}{ G } & G1 & 10:00 & 02:00 & 09:02 & 02:05 & 09:00 & 02:00 \\
\hline & G2 & $12: 00$ & 02:00 & 11:07 & $01: 51$ & 11:00 & 02:00 \\
\hline & G3 & 14:00 & 01:00 & $12: 59$ & $01: 22$ & 13:00 & 01:00 \\
\hline & G4 & 15:00 & 02:00 & $14: 21$ & 01:44 & $14: 00$ & 02:00 \\
\hline & G5 & $17: 00$ & 02:00 & $16: 05$ & $01: 33$ & $16: 00$ & 02:00 \\
\hline & G6 & 19:00 & 02:00 & $17: 39$ & $01: 47$ & $18: 00$ & 02:00 \\
\hline
\end{tabular}

Table 2. The distribution data model of arrival time and duration time for each attraction sequence

\begin{tabular}{|c|c|c|c|c|c|}
\hline & \multicolumn{5}{|c|}{ ATTRACTION SEQUENCE A } \\
\cline { 2 - 6 } & Johor Zoo & $\begin{array}{c}\text { Hutan Bandar } \\
\text { Recreational Park }\end{array}$ & Jalan Tan Hiok Nee & Bazaar Karat & $\begin{array}{c}\text { Danga Bay } \\
\text { Amusement Park }\end{array}$ \\
\hline Arrival time (AT) & $10: 00$ & $14: 00$ & $16: 00$ & $19: 00$ & $22: 00$ \\
\hline $\begin{array}{c}\text { Duration time } \\
\text { (DT) }\end{array}$ & $2: 00$ & $1: 00$ & $1: 00$ & $2: 00$ & $2: 00$ \\
\hline Depart Time & $12: 00$ & $15: 00$ & $17: 00$ & $21: 00$ & $00: 00$ \\
\hline $\begin{array}{c}\text { Time Differences } \\
\text { (DepT- AT) }\end{array}$ & - & $2: 00$ & $1: 00$ & $2: 00$ & $1: 00$ \\
\hline
\end{tabular}

Table 3: Attraction Sequence A of Mode Model

\begin{tabular}{|c|c|c|c|c|c|}
\hline & \multicolumn{5}{|c|}{ ATTRACTION SEQUENCE B } \\
\cline { 2 - 6 } & Johor Zoo & Johor Grand Palace & Jalan Tan Hiok Nee & Bazaar Karat & $\begin{array}{c}\text { Danga Bay } \\
\text { Amusement Park }\end{array}$ \\
\hline Arrival time (AT) & $10: 00$ & $14: 00$ & $16: 00$ & $19: 00$ & $22: 00$ \\
\hline $\begin{array}{c}\text { Duration time } \\
\text { (DT) }\end{array}$ & $02: 00$ & $01: 00$ & $01: 00$ & $02: 00$ & $02: 00$ \\
\hline Depart Time & $12: 00$ & $15: 00$ & $17: 00$ & $21: 00$ & $00: 00$ \\
\hline $\begin{array}{c}\text { Time Differences } \\
\text { (DepT- AT) }\end{array}$ & - & $02: 00$ & $01: 00$ & $02: 00$ & $01: 00$ \\
\hline
\end{tabular}

Table 4: Attraction Sequence B of Mode Model

\begin{tabular}{|c|c|c|c|c|c|c|}
\hline & \multicolumn{7}{|c|}{ ATTRACTION SEQUENCE G } \\
\cline { 2 - 7 } & $\begin{array}{c}\text { Hutan Bandar } \\
\text { Recreational Park }\end{array}$ & Johor Zoo & $\begin{array}{c}\text { Johor Grand } \\
\text { Palace }\end{array}$ & $\begin{array}{c}\text { Jalan Tan Hiok } \\
\text { Nee }\end{array}$ & Bazaar Karat & $\begin{array}{c}\text { Danga Bay } \\
\text { Amusement Park }\end{array}$ \\
\hline Arrival time (AT) & $10: 00$ & $11: 00$ & $14: 00$ & $17: 00$ & $19: 00$ & $22: 00$ \\
\hline $\begin{array}{c}\text { Duration time } \\
\text { (DT) }\end{array}$ & $02: 00$ & $02: 00$ & $01: 00$ & $02: 00$ & $02: 00$ & $02: 00$ \\
\hline $\begin{array}{c}\text { Depart Time } \\
\text { (DepT) }\end{array}$ & $12: 00$ & $13: 00$ & $15: 00$ & $19: 00$ & $21: 00$ & $00: 00$ \\
\hline $\begin{array}{c}\text { Time Differences } \\
\text { (DepT- AT) }\end{array}$ & - & $-01: 00$ & $01: 00$ & $02: 00$ & $00: 00$ & $01: 00$ \\
\hline
\end{tabular}

Table 5: Attraction Sequence G of Mode Model 


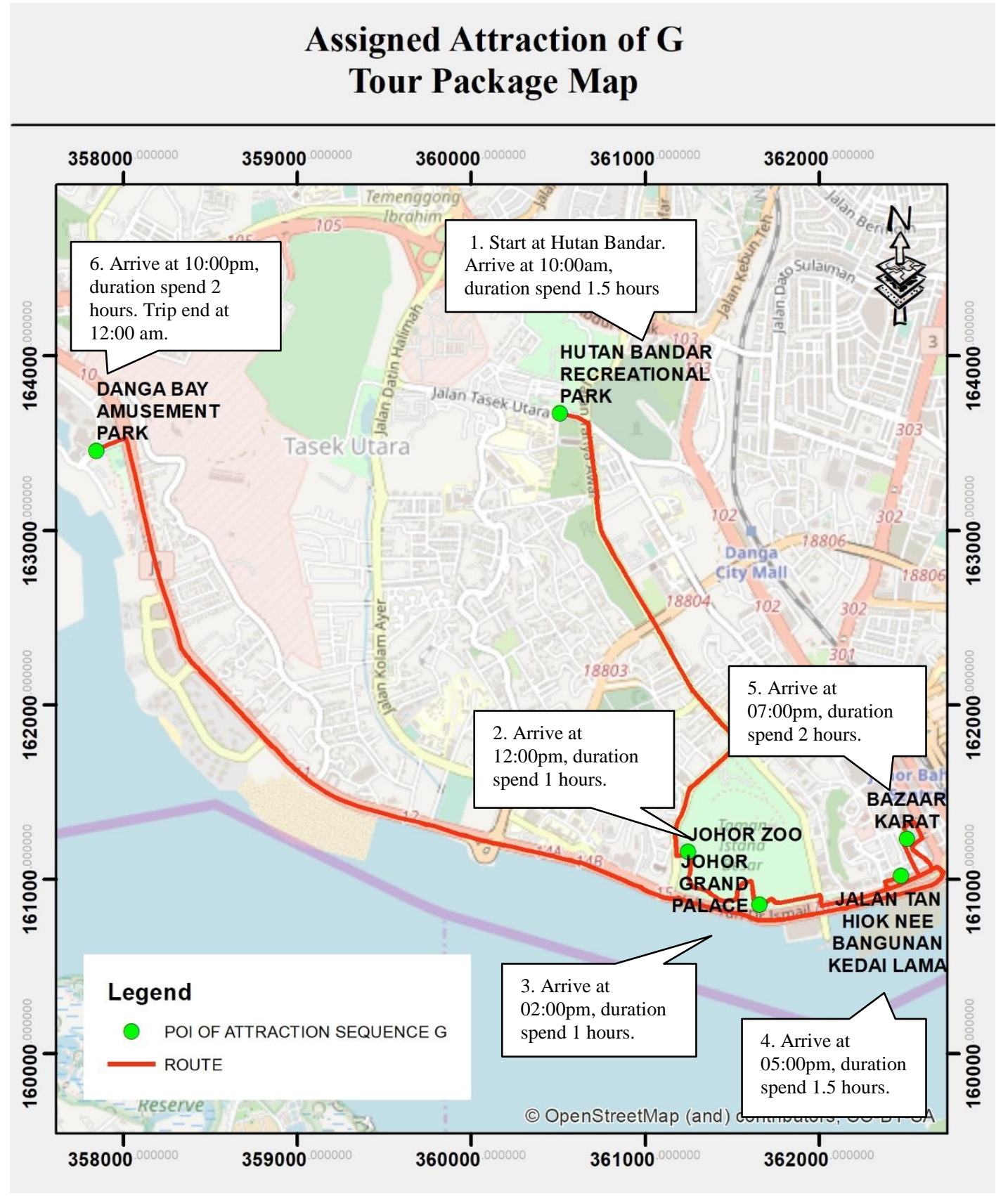

Figure 6: The map of the tour package for the assigned sequence of $G$

\subsection{Model Validation}

After obtaining the suitable model for modelling tour packages of attraction sequence $\mathrm{G}$, data validation can be feasible. The purpose of conducting data validation is to ensure the quality level of the final data (Zio et al., 2016). In this study, the method used to validate the data is the elementary statistics test, which is the Chi-Square Goodness-of-Fit Test.

Chi-Square statistics is being used to identify the frequency distribution on whether the data is fits with a specific pattern. When one is testing to see either the frequency distribution fits a certain specific pattern, the chi-square goodness-of-fit test is applicable as shown in equation 3.

As for the attraction sequence of $\mathrm{G}$ for the arrival time, the value of $X^{2}$ is 263.8143 and the value of the $P$-value 368.0416 .
The Chi-Square statistics $X^{2}$ and the $P$-value is then be compared. If the $X^{2}$ value is outside the $P$-value, it can be conclude that the observed frequencies are compatible with the expected frequencies and therefore, the model will provides a good data output (Moore et al., 2012). Since $X^{2}$ for attraction sequence $\mathrm{G}$ is smaller than the $P$-value, the distribution of data is in order.

As for the level of significance, the value of significance that has been applied in this study is $\alpha=0.05$ so as to ensure the $5 \%$ probability of error type I. Therefore, the level of significance for the arrival time of attraction sequence of $\mathrm{G}$ is 0.994 which is bigger than 0.005 , it can be conclude that the dataset has a low level of significance. 
The International Archives of the Photogrammetry, Remote Sensing and Spatial Information Sciences, Volume XLII-4/W16, 2019 6th International Conference on Geomatics and Geospatial Technology (GGT 2019), 1-3 October 2019, Kuala Lumpur, Malaysia

According to Xia, (2007), even though, the chi test value is 0.05 or less it still signifies a significant result, but the model provides a poor fit to data. Xia also strongly stated that it would still be considered poor when the value of $n$ is large.

\subsection{Various tour package based on the tourist preferences in a geospatial form for market segmentation.}

The findings of various spatial distribution maps based from Figure 2, is been constructed among the famous popular attraction sequence which are attraction sequence F, G, H and I as shown in Table 6.

\begin{tabular}{|c|c|c|}
\hline $\begin{array}{c}\text { Tour } \\
\text { Package }\end{array}$ & Code & Name Of Attractions \\
\hline \multirow{6}{*}{$\mathrm{F}$} & F1 & Johor Zoo \\
\hline & F2 & Sultan Abu Bakar Mosque \\
\hline & F3 & Johor Grand Palace \\
\hline & F4 & Jalan Tan Hiok Nee Bangunan Kedai Lama \\
\hline & F5 & Bazaar Karat / \\
\hline & F6 & Danga Bay Amusement Park \\
\hline \multirow{6}{*}{ G } & G1 & Hutan Bandar Recreational Park \\
\hline & G2 & Johor Zoo \\
\hline & G3 & Johor Grand Palace \\
\hline & G4 & Jalan Tan Hiok Nee Bangunan Kedai Lama \\
\hline & G5 & Bazaar Karat \\
\hline & G6 & Danga Bay Amusement Park \\
\hline \multirow{6}{*}{$\mathrm{H}$} & H1 & $\begin{array}{l}\text { Johor Art Gallery Museum / Figure Museum } \\
\text { Johor }\end{array}$ \\
\hline & $\mathrm{H} 2$ & Johor Zoo \\
\hline & $\mathrm{H} 3$ & Johor Grand Palace \\
\hline & $\mathrm{H} 4$ & Jalan Tan Hiok Nee Bangunan Kedai Lama \\
\hline & H5 & Bazaar Karat / \\
\hline & H6 & Danga Bay Amusement Park \\
\hline I & I1 & $\begin{array}{l}\text { Johor Art Gallery Museum / Figure Museum } \\
\text { Johor }\end{array}$ \\
\hline
\end{tabular}

\begin{tabular}{|l|l|l|}
\hline & I2 & Hutan Bandar Recreational Park \\
\cline { 2 - 3 } & I3 & Sultan Abu Bakar Mosque \\
\cline { 2 - 3 } & I4 & Johor Grand Palace \\
\cline { 2 - 3 } & I5 & Bazaar Karat / \\
\cline { 2 - 3 } & I6 & Danga Bay Amusement Park \\
\hline
\end{tabular}

Table 6: List of Attractions for Attraction Sequence F,G,H,I

It is because all four of these attraction sequence shows various different of attraction itinerary, arrival time, duration of time spent and travel route by implementing the same statistical model which is the mode model to identify the maximisation of utility of the arrival time and duration of time spent. Based on my observations and findings, I found that there are at least a small variations of the map which are;

(a) Female Demographic of Sequence F

(b) Female and Budget less than RM100 Demographic of Sequence G

By comparing the above six listed distribution map and Figure 2 , shows that only $2^{\text {nd }}$ tier and $3^{\text {rd }}$ tier is involve in implementing distribution map for the purpose of market segmentation. The variations of distribution map between all six spatial distribution map can be seen through the selection of attraction sequence according to the best of attraction sequence that has been chosen by the respondent as refer to the Figure 4 in corresponding to the output of the mode of arrival time and the mode of duration of time spent for every attraction.

The output of the distribution map of subgroups based on certain characteristics are shown in Figure 7 and Figure 8 . Model of validation for Table 6 is also been constructed and the result is significant. The procedure of the model validation is the same as refer in Section 3.3 


\section{FEMALE STUDENT TOURIST DISTRIBUTION MAP OF ATTRACTION SEQUENCE F}

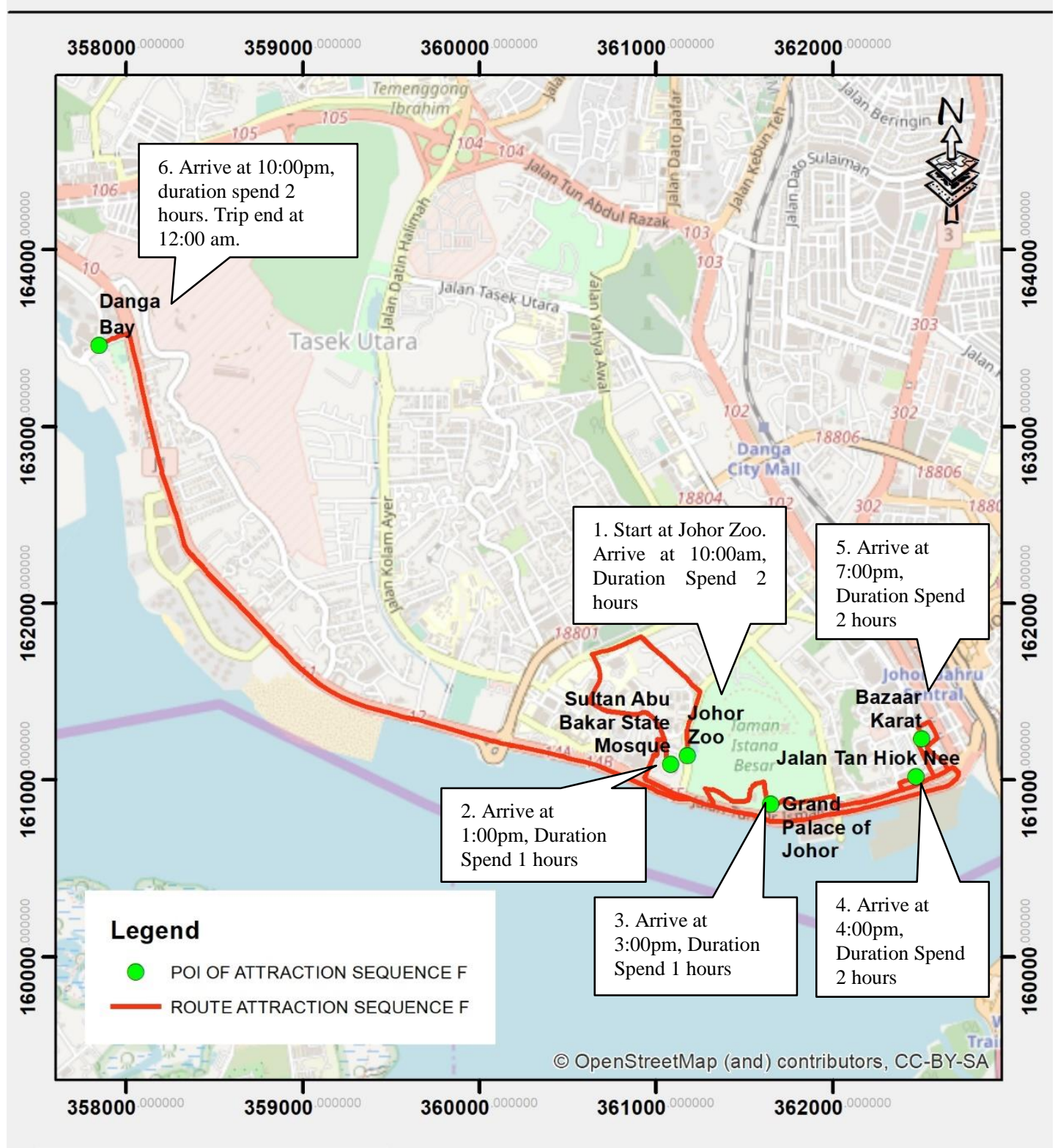

Figure 7: Mode of Arrival and Duration of time spent for Female Demographic of Sequence F 


\section{FEMALE WITH THE LOWEST BUDGET DISTRIBUTION MAP OF ATTRACTION SEQUENCE G}

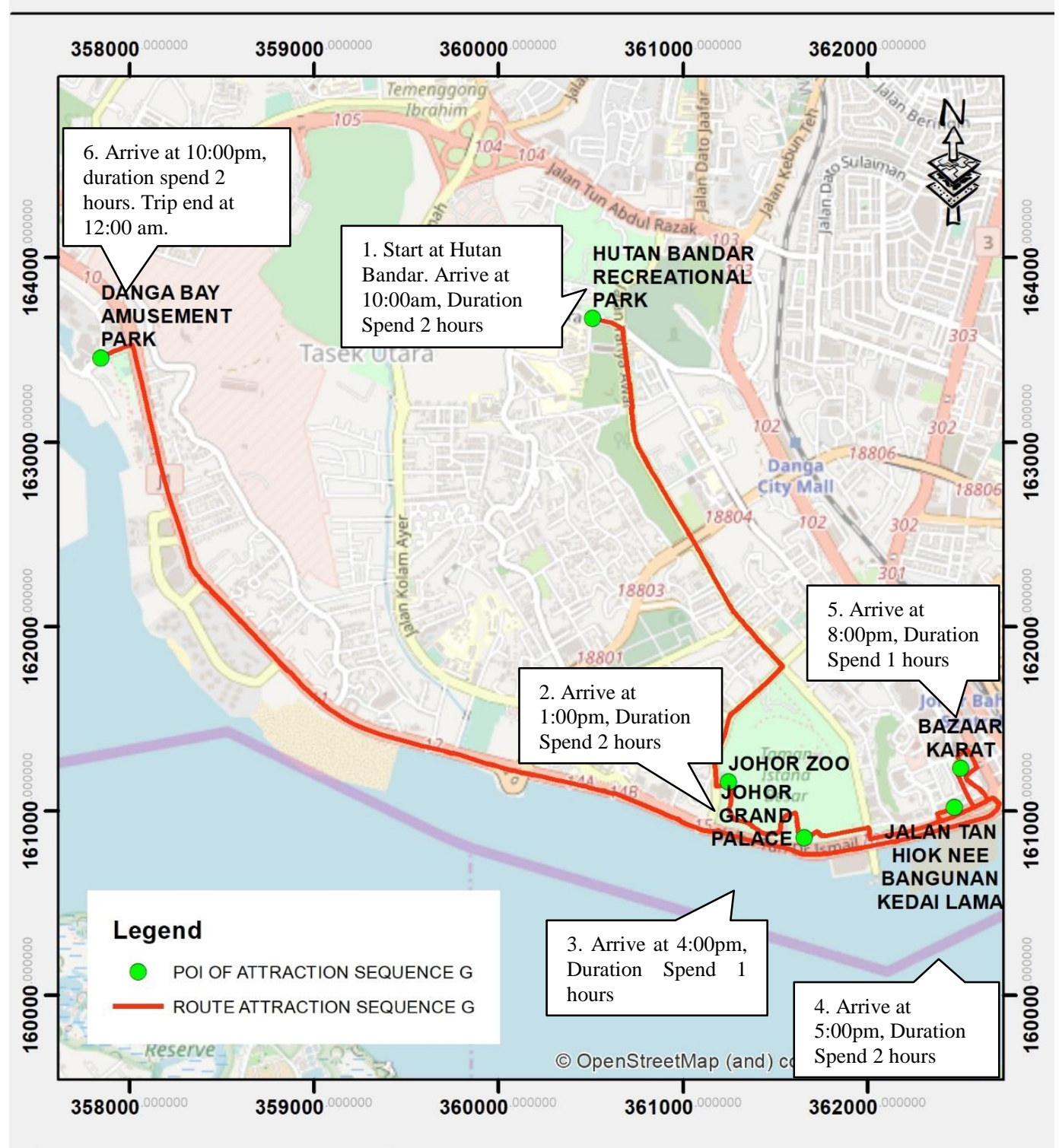

Figure 8: Mode of Arrival and Duration of time spent for Female and Budget less than RM100 Demographic of Sequence G

The implementation of the tour package in a geospatial form and the tendency of tourist market has gradually increased the market segmentation which are presumed to be relatively consistent in terms of the tourist pattern. According to J. C. Xia, (2007), the accurate and fast market positioning and also the factors of personalised service are the main frame for a tour company's success.

The strategy of market segmentation recognizes that few vacation destinations areas are universally acceptable and desired. In the first stage of marketing, dividing both market between the present and potential market on the basis of meaningful characteristics that focus on promotion, product and pricing would assist in reaching target. One of the most effective market strategy is by determining the target of markets and attempt to reach those markets. Bases of market segment can be categorised into several classes which are the Geographic, Demographic, Socioeconomic, Psychographic, Behaviour Patterns, Consumption Patterns and lastly the Consumer predispositions.

Tourism sector is known as the huge industry engage in various business activities that direct the flow of goods and services from the producer to the consumer. An unprofitable tourist facility that has the maximum utility of satisfaction would be a waste if there were no proper marketing. Therefore, tourism industries have contributed immensely towards the economic wellbeing of a country and specifically Johor Bahru has seeing the advantages of both natural and erected tourist attraction sites as it boosts the economy of the states and provides job opportunities to both indigenes and non-indigenes. 


\section{CONCLUSION}

With the above demonstrated processes that identifies the maximisation of utility for arrival time and duration time for each attraction, the aimed of the study has been achieved. As it has been stated earlier that the aim of this study is to understand and analyse the tourist movement pattern based on utility maximisation in reference of tourist preferences in Johor Bahru. The study was able to be accomplish three objectives as stated in Section 1.2.

In the first objective, identifying tourist movement based on tourist demand can be seen in section 3.1. Although the tourist movement from one attraction the next has been assigned in order to obtain the similarity of the tourist sequence, the tourist movement can still be seen. Most of the attraction sequence that has been assigned and the pattern of movement is moving around the city.

The implementation of utility maximisation of distribution data model into the top three popular assigned attraction sequence helps in making a concrete decision on which has the high maximisation of the arrival time and duration time for each attraction in modelling a tour package. Based on this study, mode model is one of the suitable model used in generating a descriptive value. therefore, to strengthen the dataset of the selected model, a data validation test is being done by using the Chi-Square Goodness-of-fit.

The last objective of creating various tour package based on the tourist preferences can be challenging because it show no variations of tourist movement. This is due to the uses of the same attraction sequence. Although, there is no variations of tourist movement, but the variation of arrival time and duration time can still be seen. Once those attractive movement patterns have been identified, further analysis can be carried out to overlay the characteristics of tourist. Therefore, the tour package can be designed and marketed to specific tourist groups.

\section{REFERENCES}

Abomeh, O., \& Nuga, O. (2013). Utilisation of GISTechnology for Tourism Management in Victoria Island Lagos. European Scientific Journal, 9(3), 92-118. Retrieved from http://www.eujournal.co.uk/index.php/esj/article/view/735/0

Akova, O., \& Cetin, G. (2017). COMPONENTS OF PACKAGE TOUR QUALITY 7th Advances in Hospitality \& Tourism Marketing \& Management ( AHTMM ) Conference, Famagusta, (January 2018), 10-15.

Asakura, Y., \& Iryo, T. (2007). Analysis of tourist behaviour based on the tracking data collected using a mobile communication instrument. Transportation Research Part A: Policy and Practice, 41(7), 684-690. https://doi.org/10.1016/J.TRA.2006.07.003

Bowie, D. - Chang, J. C. (2005) Tourist satisfaction: A view from a mixed international guided package tour. Journal of Vacation Marketing, Vol. 11 (4), 303-322

Ferreira, L. N., \& Pereira, L. N. (2014). Measuring Tourists Preferences - Which Road to Choose?, 3(2), 2-3. https://doi.org/10.4172/2167-
Gursoy D and Rutherford DG (2004) Host attitudes toward tourism: an improved structural model. Annals of Tourism Research 31(3): 495-516 Seetanah B (2011) Assessing the dynamic economic impact of tourism for island economies. Annals of Tourism Research 38(1): 291-308.

Jane, A., \& Marie, K. (2012). How Tour Operators Promote Mauritius As a Tourist Destination.

Khanan, A. (2014). Development of Tour Packages through Spatio-Temporal Modelling of Tourist Movements. Curtin University Library Curtin's Institutional Research Repository Http://Espace.Library.Curtin.Edu.Au/R?Func=dbin-JumpFull\&local_base=gen01-Era02\&object_id=204941, (October), $1-194$.

Lawler, E. (2013). The rise of experiential marketing. Advertising Age, 1-5.

Lew, A., \& Mckercher, B. (2006). MODELING TOURIST MOVEMENTS A Local Destination Analysis, 33(2), 403-423. https://doi.org/10.1016/j.annals.2005.12.002

Oh, H. - Fiore, A. M. - Jeoung, M. (2007) Measuring experience economy concepts: Tourism applications. Journal of Travel Research, Vol. 46 (2), 119-132.

Sivalingam, G. (2007). Beach Based Recreation and Tourism in Malaysia. Institute

Tourism Malaysia Promotes "Johor Holiday Packages.” (2016). Retrieved September 24, 2018, from https://www.tourism.gov.my/media/view/tourism-malaysiapromotes-johor-holiday-packages

Wu, X., Guan, H., Han, Y., \& Ma, J. (2017). A tour route planning model for tourism experience utility maximization. Advances in Mechanical Engineering, 9(10), 1-8. https://doi.org/10.1177/1687814017732309

Xia, J. C. (2007). Modelling the spatial-temporal movement of tourists. School of Mathematical and Geospatial Sciences, (February), 1-202.

Xia, J., Zeephongsekul, P., \& Packer, D. (2011). Spatial and temporal modelling of tourist movements using Semi-Markov processes. Tourism Management, 32(4), 844-851. https://doi.org/10.1016/j.tourman.2010.07.009

Revised August 2019 